\title{
Preparation and Characterization of Collagen Microspheres for Sustained Release of Steroidal Saponins
}

\author{
Chunrong Yang ${ }^{a *}$, Jianhua Wang ${ }^{b}$ \\ ${ }^{a}$ Department of Materials Science and Engineering, Fujian University of Technology, Fuzhou 350118, China \\ ${ }^{b}$ Institute of Biomedical and Pharmaceutical Technology, Fuzhou University, Fuzhou 350002, China
}

Received: July 6, 2014; Revised: September 10, 2014

\begin{abstract}
Steroidal saponins are the major pharmacological constituents of ophiopogon japonicus which have been used to treat bone and joint diseases, nerve damage, and hematischesis for hundreds of years in China. The objective of this study was to investigate the therapeutic potential of collagen microspheres loaded with steroidal saponins as an inducer factor for skeletal defects using an in vitro model. The collagen-steroidal saponins composite microspheres were prepared using a water-in-oilin-water emulsion/solvent evaporation technique. SEM micrographs showed that spherical particles with diameters of tens micrometers were successfully produced. Release kinetics was characterized by an initial burst release reducing to a linear release over the first 8 days. MTT assay showed that the cells attached on composite microspheres were more in comparison with pure collagen microspheres and stimulated significantly higher level of alkaline phosphatase than the counterpart. Moreover, composite microspheres possess osteoinductive activities as demonstrated by the ability to induce cells to commit to crystals in contact coculture. The present finding suggests that sustained delivery of steroidal saponins may be very effective in improving the osteogenic potential of collagen microspheres and the composite microspheres are useful for tissue-engineering applications.
\end{abstract}

Keywords: steroidal saponins, collagen, sustained release, bone tissue engineering, microsphere

\section{Introduction}

Many biomaterials with osteoconductivity have been developed as bone graft substitutes. Such materials provide readily available scaffolds facilitating bone ingrowth, such as collagen type I, chitosan ${ }^{1-4}$, insoluble hydroxyapatites and soluble bioglass ${ }^{5-6}$. However, alone osteoconductive materials are limited for applications because they require osteogenic cell sources and osteoinductive supplements for bone regeneration.

Steroidal saponins are the major pharmacological constituents of ophiopogon japonicus which have been used to treat bone and joint diseases, nerve damage, and hematischesis for hundreds of years in China. Previous studies have demonstrated that steroidal saponins are osteoinductive and can assure better biological performance for bone regeneration through promoting osteogenic differentiation of osteoblast via increasing the expressions of osteocalcin, alkaline phosphatase (ALP) and type I collagen, and enhancing proliferation of osteoblast by accelerating cell cycles ${ }^{7}$. Steroidal saponins can be herein prescribed for the treatment of bone and joint diseases, and the treatment regime normally consists of oral treatment or daily selfadministered injection. This dosing frequency is necessary because of the short terminal half-life of the drug, which approximately reaches 4 to 6 hours. Additionally, given the short terminal half-life, the amount would most likely be lower and smaller than the therapeutic concentration. Thus,

*e-mail: lambmeo@163.com local delivery of steroidal saponins into the diseased site would likely be necessary for effective treatment.

As one of the native constituents of bone, collagen is an attractive osteoconductive material used in bone tissue engineering. Previous studies have used collagen to premade porous scaffolds and the drugs were impregnated in these structures after the fabrication ${ }^{8-9}$. In the present study, steroidal saponins were suspended in a solution of collagen before the reconstitution of collagen fiber is initiated. Compared to the traditional drug impregnating approach, the advantages of this microencapsulation approach are even distribution of the encapsulated drugs throughout the microsphere, and elimination of the time-consuming and inefficient drug impregnation step.

We report herein the processing route to producing steroidal saponins-encapsulated collagen microspheres and their in vitro osteogenic performance using pre-osteoblastic MC3T3-E1 cells.

\section{Material and Methods}

\subsection{Microsphere fabrication}

Collagen microspheres were fabricated by using the water-oil-water double-emulsion technique ${ }^{10}$. In brief, the initial water-oil emulsion was formed by combining $1.2 \mathrm{mg}$ of steroidal saponins (Jinlv Co., Xi'an, China) with $20 \mathrm{~mL}$ of collagen solution $(6 \mathrm{mg} / \mathrm{mL}$ ) (Xinji Co., Chengdu, China) and sonicating the mixture at $20 \mathrm{kHz}$ for 
30 seconds. This emulsion was then pipetted into stirring 30 $\mathrm{mL}$ of liquid paraffin containing $0.4 \mathrm{~mL}$ of span 80 (Sigma -Aldrich Co., Saint Louis, USA) and continued to be stirred at the rotating speed of $1000 \mathrm{rpm}$ for $10 \mathrm{~min}$ to form the final water-oil-water emulsion.

For crosslinking, 1-ethyl-3-(3-dimethyl aminopropyl) carbodiimide (EDC) and N-hydroxysuccinimide (NHS) (4:1 ratio) were incorporated in deionized water at a content of $2.5 \mathrm{mg} / \mathrm{mL}$. Then $2 \mathrm{~mL}$ of EDC/NHS solution was added to the double emulsion and kept stirring for $1 \mathrm{~h}$ to form collagen microspheres. $50 \mathrm{ml}$ of $50 \%(\mathrm{v} / \mathrm{v})$ ethanol was added into the mixture and stirred for $5 \mathrm{~min}$ to separate the collagen microspheres from oil phase. The mixture was centrifuged at 3,500 rpm for $5 \mathrm{~min}$ to remove oil phase. Then phosphate buffered-saline (PBS) was added to the collagen pellet and mixed and centrifuged at 3,500 rpm for $5 \mathrm{~min}$. This procedure was repeated three times to remove crosslinker and residual ethanol. The resulting microspheres were then washed three times with deionized water and freeze-dried in a freeze-dryer at $-60{ }^{\circ} \mathrm{C}$ for $12 \mathrm{~h}$.

For the purpose of comparison, pure collagen microspheres without the encapsulation of steroidal saponins were also prepared following the same procedure.

\subsection{Sample characterization}

\subsubsection{Particle size and surface morphology}

The diameter and surface morphology of the microspheres were determined using scanning electron microscopy (SEM) (S-3400N, Hitachi Co., Tokyo, Japan). Briefly, the microspheres were stirred in PBS overnight to homogenously disperse and air-dried onto aluminum plates. Then the samples were coated with gold for observation and varying levels of magnification.

\subsubsection{Release profile}

To determine the extent of release of steroidal saponins from the steroidal saponins-encapsulated collagen microspheres, an in vitro release experiment was performed and the release profile was obtained by incubating $10 \mathrm{mg}$ of steroidal saponins-encapsulated collagen microspheres in 10 $\mathrm{mL}$ of PBS at $37^{\circ} \mathrm{C}$ with gentle shaking. After specific time periods, the sample was centrifuged, the supernatant was collected, and microspheres were resuspended in fresh PBS. The steroidal saponin content of supernatant collected for each interval was determined by using the ultra performance liquid chromatography (UPLC, Waters Co., Milford, USA), and steroidal saponins were used as the standard.

To assess the degradability of the collagen microspheres in PBS, protein content was measured using a bicinchoninic acid protein assay kit as previously described ${ }^{11}$.

\subsubsection{Cell growth and ALP activity}

The growth kinetics of MC3T3-E1 cells (Riken Cell Collection, Saitama, Japan) on both groups of microspheres were evaluated using a 3-(4,5-dimethyl-2-thiazolyl)-2,5diphenyl-2H tetrazolium bromide (MTT) (Sigma Co., Saint Louis, USA) assay as previously described. The cells $\left(2 \times 10^{3}\right.$ cells $/ \mathrm{mL}$ ) were seeded on $10 \mathrm{mg}$ of samples placed on each well of 24-well plates (Corning Co., Midland, USA), and the cells were allowed to attach to the samples and to remain undisturbed in a humidified incubator $\left(37{ }^{\circ} \mathrm{C}\right.$ and $\left.5 \% \mathrm{CO}_{2}\right)$ for 1,3 , or 5 days. At the indicated time points, the medium was removed and $200 \mathrm{ml}$ MTT solution was added to each well. Following incubation in a fully humidified atmosphere $\left(37^{\circ} \mathrm{C}\right.$ and $5 \% \mathrm{CO}_{2}$ ) for $2 \mathrm{~h}$, MTT was then taken up by active cells and reduced in the mitochondria to insoluble purple formazan granules. Subsequently, the medium was removed and precipitated formazan was dissolved in dimethyl sulfoxide (DMSO) (Sigma Co., Saint Louis, USA), then optical density of the solution was measured using a microplate spectrophotometer at a wavelength of $540 \mathrm{~nm}$. The MTT absorbance data were converted into cell numbers based on the standard curve obtained on a plastic culture dish. Five samples were arbitrarily selected from each co-culture group for the MTT assay.

Cells seeded at 2 different densities $\left(1 \times 10^{4}\right.$ cells $/ \mathrm{mL}$ and $3 \times 10^{4}$ cells $/ \mathrm{mL}$ ) on $20 \mathrm{mg}$ of encapsulated-microspheres or pure-microspheres were cultured for 7 days, respectively. The amount of ALP secreted by the cells were measured using the activity detection kits of alkaline phosphatase and bicinchonininc acid (lianshi Co., Shanghai, China), and the corresponding concentration was normalized. Five replicate samples were used for each condition.

The morphology of $1 \times 10^{3}$ cells per milliliter of serumcontaining medium grown on the microspheres (steroidal saponins-encapsulated or pure collagen) for 10 days was observed using a phase contrast microscope (Olympus IX 71, Tokyo, Japan). The crystals mineralized by cells were examined with energy dispersive X-ray (EDX) spectrometry (XL30, Philips Co., Eindhoven, The Netherlands) for analysis of calcium and phosphorus and their relative distribution in the samples. In addition, the quantities of these elements were detected, and the calcium to phosphorus ratios calculated.

\subsection{Statistical analysis}

Statistical analysis was performed using student's t tests, and the significance level was set at $\mathrm{p}<0.05$. The error bars indicate the standard deviation of the mean.

\section{Results and Discussion}

\subsection{Characterization of microspheres}

The particle size and surface morphology were determined by scanning electron micrographs (SEM). For both of the encapsulated and pure microspheres, spherical microparticulates were produced well (Figure 1a, b). Their diameter ranged from several microns up to about $100 \mathrm{~mm}$. On closer examination, the surface of the encapsulated microspheres was observed to be rough (Figure 1c), whereas that of the pure-collagen microspheres was much smoother (Figure 1d). Drugs were evenly entrapped within the collagen matrix.

The present study provides the double-emulsion technique for easy control of particle diameter of collagen microspheres by controlling the surfactant concentration and rotating speed of the emulsified mixture ${ }^{12}$. However, one limitation of this technique is maintaining collagen stability and activity during the fabrication process. The organicaqueous interface can interfere with the hydrostatic mediated 


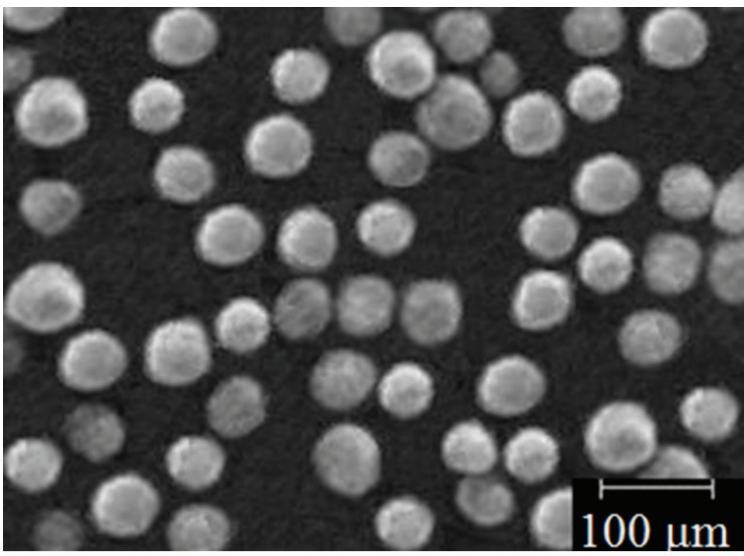

(a)

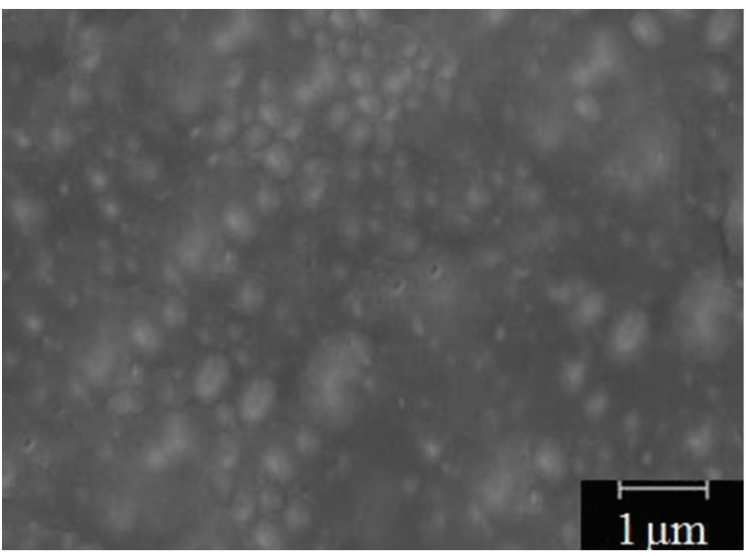

(c)

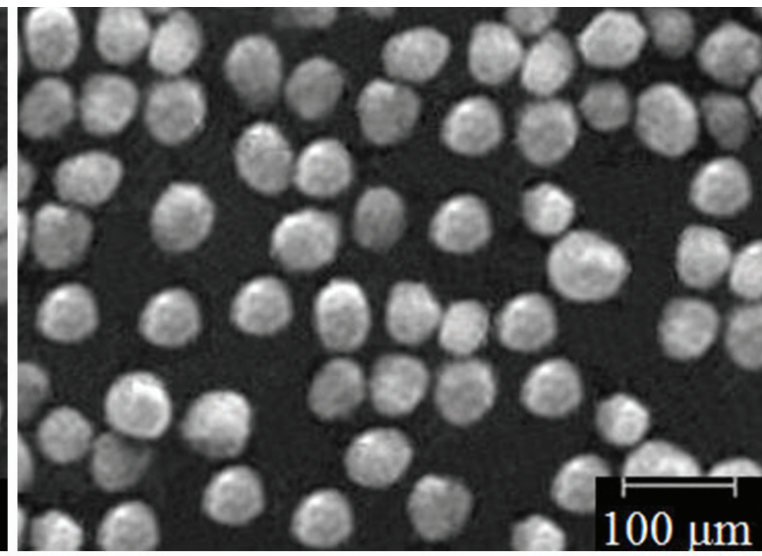

(b)

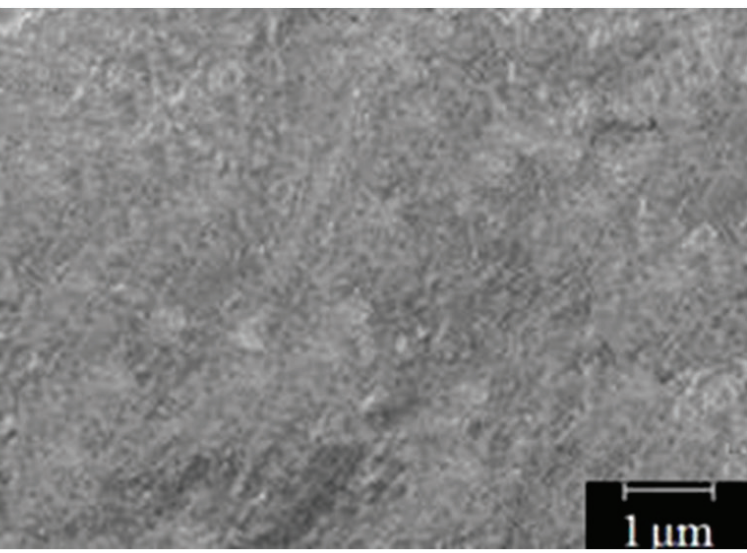

(d)

Figure 1. Scanning electron micrographs of the microspheres: $(a, c)$ collagen microspheres encapsulating steroidal saponins and (b,d) pure collagen microspheres. (c) and (d) are magnifications of (a) and (b), respectively.

tertiary structure of collagen, and the mechanical cavitation forces present during emulsification can denature collagen ${ }^{13}$, suggesting that the drug would rapidly diffuse away from the delivery site. To address this limitation, crosslinking due to EDC/NHS in our laboratory was applied. Another important consideration when evaluating the potential of crosslinking is the fact that crosslinking of collagen can create optimal fiber density of the meshwork entrapping the steroidal saponins upon fiber reconstitution and matrix solidification, which should be the most important feature of the collagen microsphere contributing to osteoconduction. Crosslinker EDC/NHS used in this study is known to be biocompatible because EDC/NHS do not persist in the linkage between collagen molecules and are simply washed away after crosslinking ${ }^{14}$.

Among the different formulations, microspheres composed of collagen and steroidal saponins are of special interest in the treatment of bone defect, because the size tuned micro-carriers allow the drugs to be tailored and released in a controlled manner for specific targeting. Moreover, the microscale-tailored particles can be effectively injected into lesions with minimal surgical invasion. The steroidal saponins-collagen microparticulates are herein considered to be particularly useful for the repair of skeletal defects by being directly implanted into the defective sites to repopulate osteoprogenitor cells. In such case, the microspheres should have high potential in terms of their cell population and osteogenic stimulation $^{15}$.

\subsection{Release profile of steroidal saponins}

The release profile of steroidal saponins from the collagen microspheres in PBS was studied. The steroidal saponins released with a rapid rate during initial 8 days, followed by a slower release rate for the remaining duration of the experiment (Figure 2a). The total amounts of steroidal saponins released at $0-4,5-8,9-12,13-16$ and 17-20 days were $5.45,1.48,0.86,0.59$ and $0.45 \mathrm{mg} / \mathrm{mL}$, respectively (Table 1).

On the other hand, the release curve was similar to the degradation curve of the collagen microspheres in PBS (Figure 2b), indicating that the drug release could occur by degradation of the collagen microspheres. Nevertheless, the most important feature of the collagen microsphere contributing to release of steroidal saponins should be minimizing the initial burst release.

In fact, the release of steroidal saponins from the collagen microspheres is a combination of diffusion and bioerosion ${ }^{16}$. The release profile for collagen microspheres 


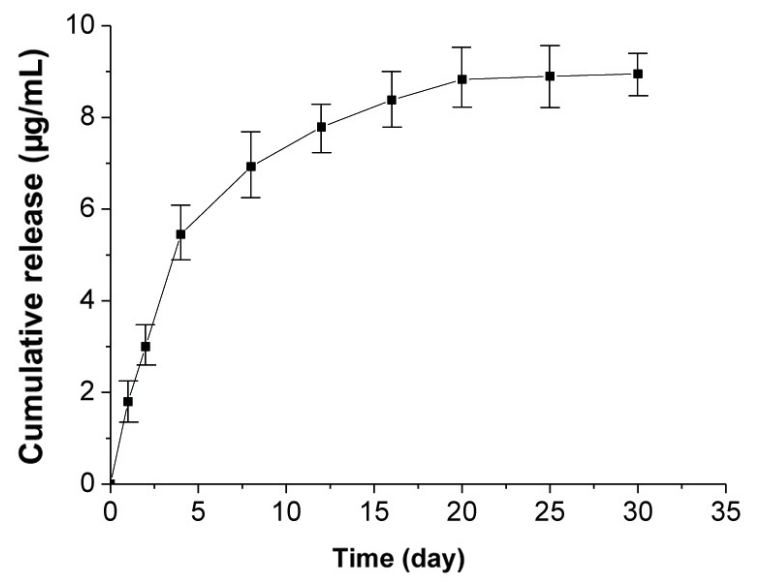

(a)

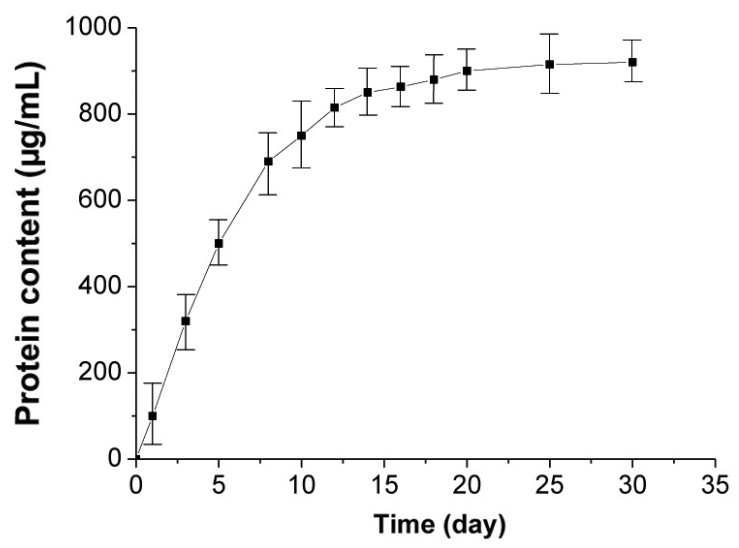

(b)

Figure 2. (a) In vitro release profile of steroidal saponins from microspheres suspended in phosphate-buffered saline under gentle agitation over 35 days. (b) In vitro degradation rate of collagen microspheres in phosphate-buffered saline. Each data point is the mean \pm standard deviation of five separate aliquots of microspheres in suspension.

Table 1. Steroidal saponin concentration in collagen microspheres conditioned media.

\begin{tabular}{cc}
\hline Media collection interval & $\begin{array}{c}\text { Concentration of steroidal } \\
\text { saponins, } \mathbf{~ m g / m L}\end{array}$ \\
\hline 0 to 4 days & 5.18 \\
5 to 8 days & 1.15 \\
9 to 12 days & 0.65 \\
13 to 16 days & 0.44 \\
17 to 20 days & 0.41 \\
\hline
\end{tabular}

is primarily dependent on bulk erosion of the collagen. By the time, the steroidal saponin release continues, which can probably be explained by degradation of collagen and high internal porosity of microsphere. During this period, the fewer steroidal saponins could diffuse out, then drugs release depend on collagen degradation. It is known that collagen can rapidly biodegrade in PBS. In this system, crosslinking results in slower degradation and extended release, allowing long term sustained delivery of the encapsulated drugs.

A key goal of sustained delivery techniques is achieving therapeutic levels of released factors over biologically relevant time scales. In a previous study, it was shown that $100 \mathrm{ng} / \mathrm{mL}$ of steroidal saponins was sufficient to induce the growth of new bone ${ }^{7}$. As shown in Table 1, cumulative steroidal saponin release was greater than $100 \mathrm{ng} / \mathrm{mL}$ for all intervals. Given that high-frequency injection of steroidal saponins to the sick site are impractical, a sustained delivery vehicle should be required to make such a therapy clinically viable.

\subsection{Cellular responses to microspheres}

Figure 3 represents the proliferation level of the cells that were grown on the collagen microspheres. The proliferated cell numbers on encapsulated microspheres was more in comparison with their pure-collagen counterparts $(P<0.05$, Figure 3), which suggested the importance of the drugs in the process of osteogenesis.

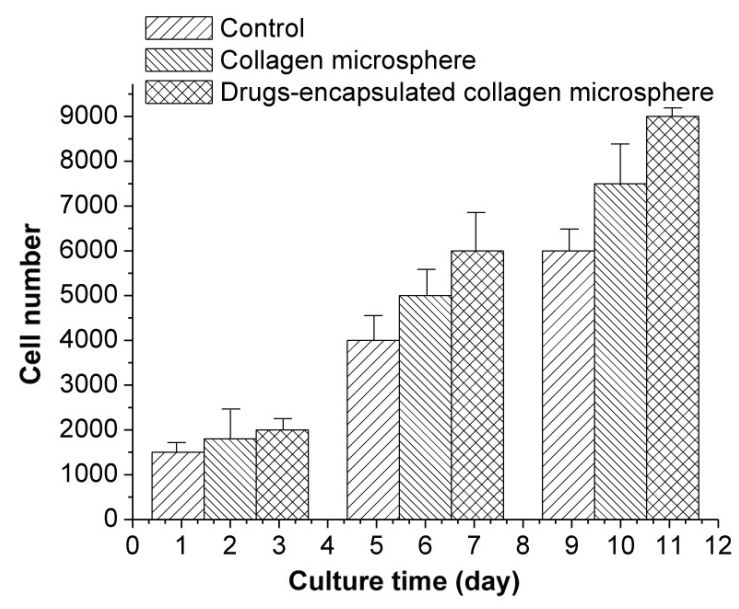

Figure 3. Proliferation of MC3T3-E1 cells on pure collagen microspheres, drugs-encapsulated collagen microspheres and control. At the indicated time points, cell viability of the drugsencapsulated collagen microsphere group was significantly higher than those of the other two groups. Data are presented as means \pm standard deviations for $\mathrm{n}=5$.

This role played by the composite microspheres in stimulating ALP gene was assessed after culturing MC3T3-E1 cells for 7 days, as shown in Figure 4. Cells seeded on $30 \mathrm{mg}$ of the microspheres with 2 initial seeding densities $\left(1 \times 10^{4}\right.$ and $3 \times 10^{4}$ cells $\left./ \mathrm{mL}\right)$ were assessed. The ALP secreted by the cells supported on the composite microspheres was significantly greater than that on the pure collagen microspheres for both culturing conditions $\left(\mathrm{p}<0.05\right.$ at $1 \times 10^{4}$ cells $/ \mathrm{mL}$ and $\mathrm{p}<0.01$ at $3 \times 10^{4}$ cells $\left./ \mathrm{mL}\right)$. Regarding the culturing condition, the ALP level appeared to be higher at the higher cell-seeding density, particularly in the composite case, suggesting that the components of composite microspheres better triggers the populated cells to elicit osteogenic traits.

The steroidal saponins adsorbed on the materials and the physicochemical properties of materials, together 


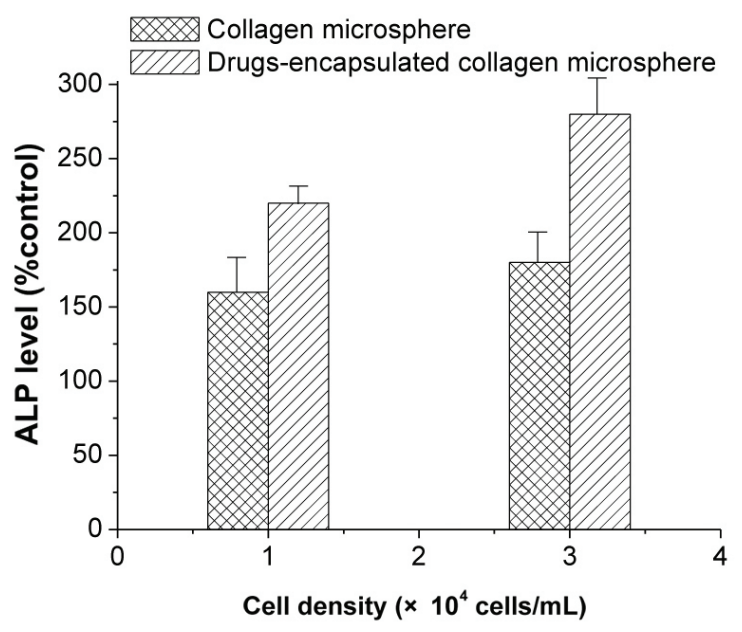

Figure 4. ALP expression level on pure collagen microspheres and drugs-encapsulated collagen microspheres after 7 days of culturing. Data are represented after being normalized to the tissue culture plate. Data are presented as means \pm standard deviations for $n=5$. Statistically significant differences $(\mathrm{p}<0.05)$ were observed between the 2 types of microspheres for each culturing condition. with other factors such as bioactivity, jointly influence the attachment, proliferation and differentiation of cells on materials. Therefore, the composite microspheres can create hydrophilic surface which consisted of physiologically active peptide sequence to engage in cell signaling by acting as ligands for cell surface receptors.

\subsection{Bioactivity of released steroidal saponins}

Phase contrast microscopy imaging was applied to observe the differentiation of MC3T3-E1 cells to evaluate whether the released steroidal saponins remained bioactive (Figure 5). Figure 5b showed that mineralization was observed after culturing MC3T3-E1 cells together with the collagen microspheres for 10 days. The components of the crystals with octahedral structure were analyzed by EDX and were shown in Figure 6. The spectrum of different elements present in the crystals during cell differentiation showed high peak heights for calcium and phosphorus. Moreover, the signals for both calcium and phosphorus in the crystals were homogeneously distributed throughout the inspected area. The average calcium and phosphorus content of the crystals were shown in the lower panel of Figure 6.

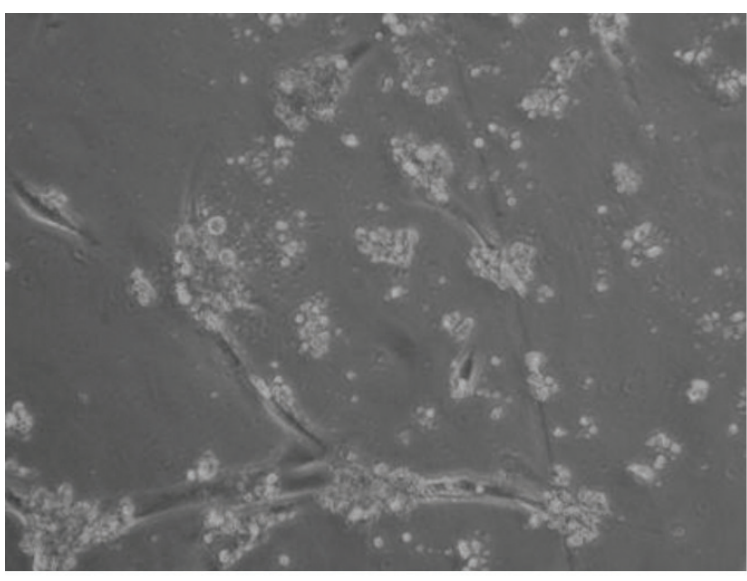

(a)

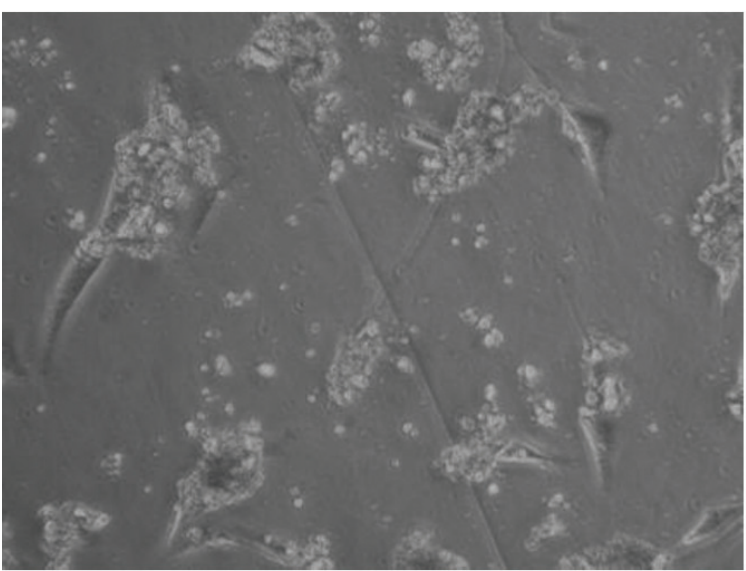

(c)

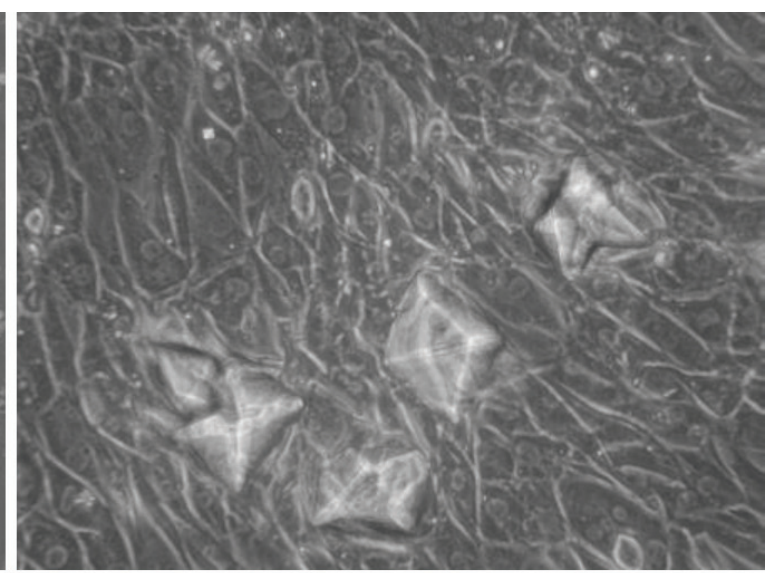

(b)

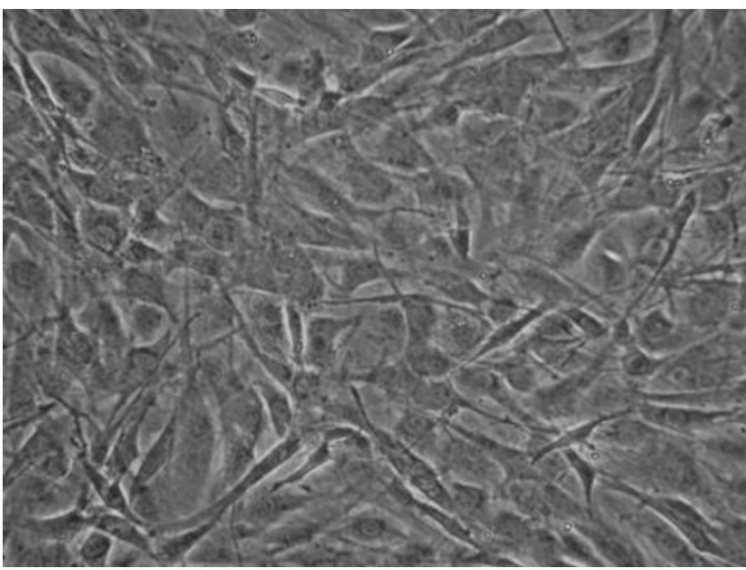

(d)

Figure 5. Phase contrast images $(\times 200)$ of crystal forming ability of MC3T3-E1 cells cultured together with collagen microspheres encapsulating steroidal saponins $(\mathrm{a}, \mathrm{b})$ and pure-collagen microspheres $(\mathrm{c}, \mathrm{d})$ for 1 day $(\mathrm{a}, \mathrm{c})$ and 10 days $(\mathrm{b}, \mathrm{d})$, respectively. 


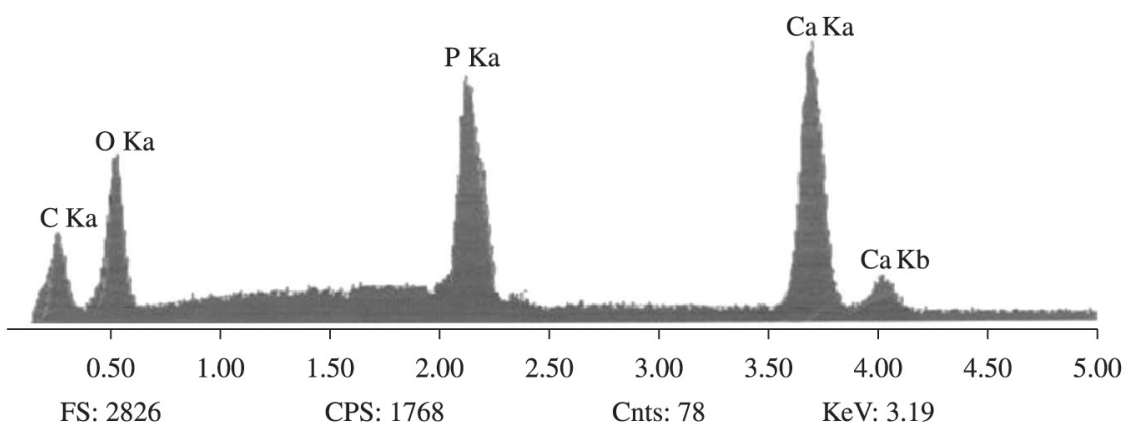

\begin{tabular}{cc}
\hline Element & Weight (\%) (Means \pm SD) \\
\hline $\mathrm{Ca}$ & $22.094 \pm 2.15$ \\
$\mathrm{P}$ & $13.491 \pm 3.24$ \\
\hline
\end{tabular}

Figure 6. Energy dispersive X-ray analysis on MC3T3-E1 cells cultured together with collagen microspheres encapsulating steroidal saponins at 10 days post differentiation. The mean values with standard deviations (SDs) for the relative composition of calcium and phosphorus are shown in the lower panel.

Calcium content analysis in native bones showed $19-26 \%$ calcium dry weight. In the current study, the calcium dry weight of the mineralized crystals after 10 days of cells differentiation was around $22 \%$, comparable to that of the native bone. Additionally, the Ca:P molar ratio was around 1.63 , close to the value of 1.67 for natural bone. These analyses indicate that the mineralized crystals are apatite, closely resembling to the natural bone tissue.

On the other hand, pure microspheres were comparatively studied. Nevertheless, no crystals occurred after 10 days of culturing (Figure 5d). Therefore, the encapsulation of steroidal saponins in microspheres successfully influenced cell differentiation toward the osteogenical lineages, as characterized by the presence of calcium phosphate within the cells over time during differentiation, which further confirmed the above results.

As a result, these osteoinductive microspheres entrapping committed steroidal saponins have the potential to be injected or transplanted to bone defects to stimulate bone formation. Moreover, the osteoinductive effects of the collagen-steroidal saponins microspheres are mediated through, at least partially, steroidal saponins, because osteogenic differentiation of MC3T3-E1 cells is not evident in contact coculture with the pure microspheres. In other word, precoating collagen with steroidal saponins can greatly improve their cell affinity. Therefore, given the proper series of signals, it may be possible to differentiate cells into crystals. Nevertheless, the source of the osteoinductive factors or substances may also partly come from the collagen meshwork, which might soak or immobilize steroidal saponins in the microspheres and then released during the coculture period ${ }^{17}$. The exact mechanisms of the osteoinductivity of the microspheres and the in vivo bioactivity of the released steroidal saponins deserve further investigations.

\section{Conclusions}

In this study, we provided evidence that steroidal saponins delivered from collagen microspheres can effectively recruite the population of the MC3T3-E1 cells and stimulate the populated cells to express ALP over the testing period. Moreover, collagen microspheres with committed steroidal saponins possess osteoinductive activities as demonstrated by the ability to induce cells to commit to crystals in contact coculture. These microspheres can be used as stable carriers for steroidal saponins delivery, and the advantage of delivering steroidal saponins could be earlier bone regeneration and faster bone formation. More broadly, the injectable composite microspheres can be excellent adjunct to existing bone scaffolds to further improve the bone regeneration. Additional future work in our laboratory will focus on developing such synergistic approaches.

\section{Acknowledgments}

This work was financially supported by natural science foundation project of Fujian (Grant no. 2014J05054). 


\section{References}

1. Shih YR, Chen CN, Tsai SW, Wang YJ and Lee OK. Growth of mesenchymal stem cells on electrospun type I collagen nanofibers. Stem Cells. 2006; 24(11):2391-2397. http://dx.doi. org/10.1634/stemcells.2006-0253. PMid:17071856

2. Kang BJ, Kim Y, Lee SH, Kim WH, Woo HM and Kweon OK. Collagen I gel promotes homogenous osteogenic differentiation of adipose tissue-derived mesenchymal stem cells in serumderived albumin scaffold. Journal of Biomaterials Science: Polymer Edition. 2013; 24(10):1233-1243. http://dx.doi.org/ 10.1080/09205063.2012.745717. PMid:23713425

3. Donzelli E, Salvadè A, Mimo P, Viganò M, Morrone M, Papagna R, et al. Mesenchymal stem cells cultured on a collagen scaffold: In vitro osteogenic differentiation. Archives of Oral Biology. 2007; 52(1):64-73. http://dx.doi.org/10.1016/j. archoralbio.2006.07.007. PMid:17049335

4. Han S, Zhao Y, Xiao Z, Han J, Chen B, Chen L, et al. The threedimensional collagen scaffold improves the stemness of rat bone marrow mesenchymal stem cells. Journal of Genetics and Genomics. 2012; 39(12):633-641. http://dx.doi.org/10.1016/j. jgg.2012.08.006. PMid:23273767

5. Nilsson M, Zheng MH and Tägil $\mathrm{M}$. The composite of hydroxyapatite and calcium sulphate: a review of preclinical evaluation and clinical applications. Expert Review of Medical Devices. 2013; 10(5):675-684. http://dx.doi.org/10.1586/1743 4440.2013.827529. PMid:24053255

6. Goel SC, Singh D, Rastogi A, Kumaraswamy V, Gupta A and Sharma N. Role of tricalcium phosphate implant in bridging the large osteoperiosteal gaps in rabbits. Indian Journal of Experimental Biology. 2013; 51(5):375-380. PMid:23821825.

7. Wang YZ, Wang JJ, Liang JC and Chen Y. Effects of diosgenin on cell proliferation, differentiation and OPG/RANKL mRNA expression of rat osteoblasts cultured in vitro. China Journal of Traditional Chinese Medicine and Pharmacy. 2010; 25(1):134136.

8. Matsuse D, Kitada M, Ogura F, Wakao S, Kohama M, Kira $\mathrm{J}$, et al. Combined transplantation of bone marrow stromal cell-derived neural progenitor cells with a collagen sponge and basic fibroblast growth factor releasing microspheres enhances recovery after cerebral ischemia in rats. Tissue Engineering Part A. 2011; 17(15-16):1993-2004. http://dx.doi.org/10.1089/ ten.tea.2010.0585. PMid:21457094
9. Nagai N, Kumasaka N, Kawashima T, Kaji H, Nishizawa $\mathrm{M}$ and Abe T. Preparation and characterization of collagen microspheres for sustained release of VEGF. Journal of Materials Science: Materials in Medicine. 2010; 21(6):18911898. http://dx.doi.org/10.1007/s10856-010-4054-0. PMid:20232232

10. Cohen S, Yoshioka T, Lucarelli M, Hwang LH and Langer R. Controlled delivery systems for proteins based on poly(lactic/ glycolic acid) microspheres. Pharmaceutical Research. 1991; 8(6):713-720. http://dx.doi.org/10.1023/A:1015841715384. PMid:2062800

11. Nagai N, Yunoki S, Suzuki T, Sakata M, Tajima K and Munekata M. Application of cross-linked salmon atelocollagen to the scaffold of human periodontal ligament cells. Journal of Bioscience and Bioengineering. 2004; 97(6):389-394. http:// dx.doi.org/10.1016/S1389-1723(04)70224-8. PMid:16233648

12. Gorth DJ, Mauck RL, Chiaro JA, Mohanraj B, Hebela NM, Dodge GR, et al. IL-1 ra delivered from poly(lactic-co-glycolic acid) microspheres attenuates IL-1 $\beta$-mediated degradation of nucleus pulposus in vitro. Arthritis Research \& Therapy. 2012; 14(4):R179. http://dx.doi.org/10.1186/ar3932. PMid:22863285

13. van de Weert M, Hennink WE and Jiskoot W. Protein instability in poly(lactic-co-glycolic acid) microparticles. Pharmaceutical Research. 2000; 17(10):1159-1167. http:// dx.doi.org/10.1023/A:1026498209874. PMid:11145219

14. Yang CR. Enhanced physicochemical properties of collagen by using EDC/NHS-crosslinking. Bulletin of Materials Science. 2012; 35(5):913-918. http://dx.doi.org/10.1007/s12034-0120376-5.

15. Kim HW, Gu HJ and Lee HH. Microspheres of collagenapatite nanocomposites with osteogenic potential for tissue engineering. Tissue Engineering. 2007; 13(5):965-973. http:// dx.doi.org/10.1089/ten.2006.0299. PMid:17425498

16. Nojehdehian H, Moztarzadeh F, Baharvand H, Nazarian $\mathrm{H}$ and Tahriri M. Preparation and surface characterization of poly-L-lysine-coated PLGA microsphere scaffolds containing retinoicacid for nerve tissue engineering: in vitro study. Colloids and Surface B: Biointerfaces. 2009; 73(1):23-29. http://dx.doi. org/10.1016/j.colsurfb.2009.04.029. PMid:19520554

17. Chan BP, Hui TY, Wong MY, Yip KH and Chan GC. Mesenchymal stem cell-encapsulated collagen microspheres for bone tissue engineering. Tissue Engineering Part C: Methods. 2010; 16(2):225-235. http://dx.doi.org/10.1089/ten. tec.2008.0709. PMid:20367213 